\title{
O CONCEITO DE PULSÃO DE MORTE NA OBRA DE FREUD*
}

J osé Gutiérrez-Terrazas

Professor titular daUniversidade Autônomade

Madri; psicanalista, membro titular da Associação Psicanalítica de Madri (IPA).

RESUMO: 0 autor postula que 0 conceito de "pulsão de morte" na obra de Freud suscita confusão dentro do pensamento psicanalítico porque, embora encadeado com a descoberta original freudiana de uma psicossexualidade inconsciente, vinculada à fantasia, auto-erótica e anárquica, por outro lado favorece a idéia de uma dinâmica psíquica de tipo biológico e inato, que faz do conflito psíquico um conflito de ordem instintiva - que por definição é insuperável.

Palavras-chave: Pulsão versus instinto, sexualidade anárquica/ afuncional versus sexualidade genitalizada/ instintiva, princípio de inércia - princípio de constância, agressividade - força psíquica autônoma?, pulsão de morte - destrutividade ou ataque intrapsíquico?

ABSTRACT: The concept of death drive in Freud's work. The Author postulates that the concept of a "death drive" in Freud's work arouses bewilderment in the psychoanalytic thought, because even though it's linked with the original Freudian discovery of an unconscious, fantasy related, autoerotical and anarchic psychosexuality, on the other hand it favors the idea of a psychic dynamics of a biologic and innate kind, which makes of the intrapsychic conflict a conflict of an instinctive kind - which by definition is unsurpassable.

Keywords: Drive versus instinct; anarchic versus genitalized sexuality; death drive as destructiveness or as intrapsychic attack.

\footnotetext{
* Texto inédito. Título do original: El concepto de pulsión de muerte en la obra de Freud. Tradução: Pedro Henrique Bernardes Rondon. A tradução foi revista pelo autor.
} 


\section{$\mathrm{O}^{-1}$} conceito de pulsão de morte, elaborado por Freud, é problemático e comlexo, uma vez que está atravessado do princípio ao fim pelas vicissitudes de um pensamento como o freudiano, que, pela ruptura radical que produz do ponto de vista epistemológico - está profundamente desgarrado em relação à ordem biológica, adaptativa ou natural.

Em vista desse desvio fundante de seu terreno específico, só podemos mesmo nos deparar com um pensamento nada homogêneo e que não está em evolução constante, diga-se abertamente - em contraposição à visão doutrinária que tem caracterizado e, com certa freqüência caracteriza, o discurso psicanalítico pós-freudiano. Diante disso, convém avançar por partes e caminhar segundo diversas gradações.

Em primeiro lugar, é preciso começar apontando que a teoria da pulsão de morte foi proposta por Freud como "puramente especulativa", ou como uma hipótese, "pela curiosidade de saber aonde leva" (FREUD, 1920, p. 24), segundo as expressões utilizadas pelo próprio Freud em Além do princípio do prazer, considera do de modo geral como aquele que introduz a pulsão de morte em sua obra.

Mas para poder dar esse passo especulativo e curioso, Freud já contava com toda uma longa trajetória de pensamento. Nela, embora - por um lado - 0 pulsional estivesse diferenciado do instintivo e, com o conceito de pulsão, sua obra claramente desse conta de uma dinâmica psicossexual como origem do conflito psíquico, por outro lado, no entanto, durante seu trabalho de conceituação sobre a pulsão - que se produz especialmente através dos Três ensai os sobre a teoria da sexualidade, de 1905, e a partir daí até 0s instintos e suas vicissitudes, de 1915 - em seu pensamento a propósito dos fundamentos da psicossexualidade foi-se gerando uma mudança muito importante, que ajudou a voltar a uma concepção endogenista por excelência da sexualidade; isto é, uma concepção claramente instintivista, ao ponto de o instinto ancorado na filogênese não deixar de assediar e atormentar o pensamento freudiano.

Assim, pois, na obra de Freud, temos um movimento contraditório a propósito da pulsão, já que, ao mesmo tempo que esta é separada e arrancada do instintivo - e ainda: por mais que a descoberta freudiana inicial de uma sexualidade anárquica, a-funcional e "demoníaca" certamente supusesse uma clara ruptura em relação à sexualidade genitalizada e instintiva - o endógeno instintivista é reintroduzido no pulsional.

Freud conta com essa trajetória dupla e contraditória na hora de atirar-se novamente sobre seu conceito de pulsão e entende-se bem - e até se contempla com olhos esperançosos o fato de que quei ra formar uma hipótese especulativa ou de que queira lançar-se numa nova aventura conceitual, impelido tanto por uma certa "curiosidade científica" (FREUD, 1920, p. 57), quanto por algumas enigmáticas observações procedentes da prática psicanalítica, em especial a 
"compulsão à repetição", que tanto contraria o "império do princípio de prazer" (Idem, p. 29) e que é postulada como "o mais originário" ou "mais elementar" do funcionamento psíquico.

Ora, para onde se dirigem os primeiros passos dessa aventura? É evidente que, como se depreende de um minucioso estudo de Além do princípio do prazer, levam-no à "afirmação do caráter regressivo das pulsões" (Idem, p. 57), isto é, levam-no a defender "a hipótese de que todas as pulsões querem reproduzir algo anterior" (Idem, p. 37), o que vincula estreitamente a pulsão de morte ao princípio de Nirvana, definido como "a tendência dominante da vida anímica, e talvez da vida nervosa em geral, de baixar, manter constante, suprimir a tensão interna de estímulo" (Idem, p. 54).

U ma proposição que o leva a pensar que a pulsão de morte é regida pelo "princípio de Nirvana" ou que este princípio é súdito da pulsão de morte, o que vem a dar no mesmo, porque em ambas as circunstâncias trata-se de considerar que a meta da pulsão de morte é levar a inquietação ou a tarefa da vida para 0 inorgânico. 0 que, em vista dessa "aspiração mais universal de tudo o que é vivo a voltar para trás, até o repouso do mundo inorgânico" (Idem, p. 60), implica colocar o pulsional na ordem do vital ou no adaptativo, de acordo com o "modelo metabiológico e metacosmológico presente na especulação de Além do princípio do prazer". ${ }^{1}$

A este propósito creio que não só é oportuno e legítimo, mas também fundamental, destacar que a tendência à descarga total da quantidade de excitação, ou o chamado "princípio de inércia neuronal" (também definido por Freud como "princípio de Nirvana", como tendência ao desinvestimento absoluto) não rege os destinos da vida psíquica como vida pulsional ou sexual, mas somente os modos de evacuação daquilo que é da autoconservação ou das necessidades que se propõem ao ser vivo com a finali idade de manter-se em vida. Isto é, o modelo de abaixamento da tensão e da homeostase é um modelo exclusivamente instintivo, nada pulsional.

Dito em outros termos,

"a necessidade de alimentação pode ser zerada, isto é, pode-se obter um nível de saciedade do ponto de vista biológico, mas aquilo que constitui um a mais irredutível ou impossível de evacuar e que obriga a adotar modos de derivação de outra ordem, aquilo que pode ser recalcado, tornado vicariante em seus destinos, aquilo que se recusa à descarga total irrompe no organismo ou no ser vivo humano alterando para sempre seu modo de funcionamento". (BLEICHMAR, 1993, p. 33)

${ }^{1}$ Termos empregados por LAPLANCHE, 1995/ 1997, p. 209. 
E é precisamente o fato de que há algo em relação a que não há possibilidade de fuga (algo que Freud denomina pulsão) que vai produzir ou impor variações que levarão da inércia (tendência à descarga absoluta, ao zero) à constância, uma constância que se inscreve no interior da série prazer-desprazer.

0 princípio de constância não é, pois, um equivalente do princípio de inércia neuronal, ou da tendência à descarga a zero, mas sim efeito de sua alteração, que obriga à constância ou à manutenção de um mínimo de quantidades. Isto é, um certo tipo de estímulo (esses estímulos endógenos dos quais não se pode fugir) fará variar desde um início, ou desde o começo do devir humano (em vista da presença de um outro que, ao satisfazer as necessidades biológicas, introduz uma variável que não se deixa satisfazer pelas vias biológicas ou de autoconservação), o destino da descarga opondo-se ao princípio de inércia.

Portanto, não é o princípio de inércia neuronal, ou princípio do zero, que está operando, mas sim algo que está impossibilitado de ligar-se e, conseqüentemente, de descarregar, que fixa um modo de descarga que leva a uma compulsão à repetição traumática. Mas então essa compulsão não é "o mais originário" ou "o mais elementar", da hipótese de Freud a esse respeito. Dito de outro modo: a compulsão à repetição não é a origem, não é o ponto de partida, mas sim uma conseqüência da presença do pulsional no ser humano, ou no funcionamento do psiquismo.

Definitivamente, e como J. Laplanche apontou num de seus múltiplos trabaIhos sobre essa questão, os "disparates" propostos por Freud em sua especulação de Além do princípio do prazer (veja-se essa longa discussão nas páginas 42-49, acerca da imortal idade das "células germinativas", que extrapola diretamente a teoria da libido, e da qual Freud tira uma conclusão contrária àquilo que essas experiências mostram; ou, também às páginas 36-41, a idéia da prioridade de um estado de morte, isto é, de que o vivo procede do inanimado e, em conseqüência, o ser vivo só pode mesmo tender para a morte, porquanto esta 0 precedeu; assim como essa retomada, às páginas 56-57, do mito deAristófanes, não para questioná lo, como o fizera nos Três ensai os sobre a teoria da sexualidade, mas para assumi-lo e apresentá-lo como modelo originário ou protótipo de Eros, proposto como pulsão de vida) "parecem significar que a morte para a qual a pulsão de morte aponta não é a morte do organismo psicobiológico, mas a morte desse 'organismo' que, no ser humano, representa os interesses do organismo biológico, ou seja, o eu" (LAPLANCHE, 1992, p. 276).

Desde logo é possível objetar, com alguma razão, que Freud tanto pela exigência epistemológica que Ihe era imposta pelo ideal científico de tipo positivista, como por sua formação biomédica, não dispunha de outro caminho senão o da metáfora biológica ou o da metacosmologia, para dar conta das bases do conflito psíquico e daquilo que, em psicanálise, se denomina " 0 
originário". Mas é que o meio de que o indivíduo se serve, ou o caminho que utiliza para a argumentação, não deixa de interferir e mediatizar essa argumentação.

De fato, o próprio Freud o considerava desse modo quando tinha pela frente, ou quando discutia, a argumentação de outros. Decerto, e muito significativamente, é possível constatar isso de maneira irretocável na discussão que se originou numa das sessões das quartas-feiras da chamada "Sociedade Psicanalítica deViena", à base daquilo que Freud qualificava como "a primeira emergência da idéia de uma pulsão de destruição na bibliografia psicanalítica" (FREUD, 1930, p. 116), idéia ante a qual ele próprio admite, nesse texto de 1930, não ter sido a princípio receptivo.

De fato, a idéia de um instinto de morte normal no ser humano foi promovida inicialmente por Sabina Spielrein, na sessão de 29 de novembro de 1911, durante a qual teve a oportunidade de apresentar resumidamente as idéias desenvolvidas num trabalho seu intitulado "A destruição como causa do devir". Para a dra. Spielrein, tal como foi anotado por O. Rank na ata dessa sessão (Les premiers psychanalystes, 1910-11/ 1979, III, p. 319-325), o componente da morte estava contido no próprio instinto sexual; trata-se de um componente destrutivo inerente a esse instinto e indispensável para o processo do devir, de modo tal que a destruição é a causa do devir.

Ora, por mais que Sabina Spielrein situasse a morte no interior do instinto sexual e remetesse a psicose e a neurose aos distintos graus de dissonância entre os dois componentes da sexualidade, toda a base de sua argumentação, ${ }^{2}$ não obstante, estava certamente apoiada tanto em dados biológicos (de fato, assim se intitula a primeira parte de seu artigo, na qual apresenta 0 instinto sexual como "estático", por estar dirigido a proteger o indivíduo, e como um caso particular do instinto "dinâmico" de procriação da espécie ou de transformação, que tem como objeto a modificação do indivíduo e exige a destruição do instinto sexual), como em uma clara referência à mitologia (pois seu trabalho conclui-se com uma seção que tem o título de "Vida e morte em mitologia", no qual expõe de modo especial como o tema da morte é tratado na mitologia à maneira de símbolo salvador, já que se a morte aparece como destrutiva no plano do instinto sexual, todavia é sinônimo de devir no plano da transformação).

Freud se acautela bem quanto a isso e apresenta-lhe, durante a discussão, algumas objeções que são dirigidas precisamente a questionar os fundamentos e os meios de que a argumentação de S. Spielrein se serve, pois, por um lado, aponta que, assim como C. G. Jung, ela utiliza o material mitológico de uma ma-

${ }^{2}$ Cf., para toda esta determinação, REXAND, 1997, p. 478-487. 
neira direta e imediata, ${ }^{3}$ sem submetê-lo ao esclarecimento psicanalítico e, por outro, vai pôr ênfase em defender a ontogênese ou o individual, ante a insistência na premissa biológica da espécie humana: “nossa hipótese psicológica [...] deve ser estabelecida sobre estádios da psicologia individual. Contra nossa concepção psicológica, a oradora tentou fundamentar a teoria das pulsões sobre premissas biológicas (tais como a conservação da espécie)" (Les premiers psychanalystes, p. 324-325).

Mas o que resulta mais significativo é que Freud, na hora de construir e fundamentar seu conceito de pulsão de morte, recorre precisamente a argumentos que têm como bases de referência tanto à biologia (da qual se vale trasladando a morte psíquica ou a autodestruição à vida biológica em seu conjunto, ao recorrer a esse estado originário da matéria orgânica sem vida), como à mitologia (ao servir-se do mito de Aristófanes para dar conta das pulsões de vida ou de um Eros, cujo objetivo final fica colocado em al cançar uma vida amorosa harmoniosa e bem adaptada, pois cada um por natureza tenderia a reencontrar sua alma gêmea, ou melhor, seu corpo irmão), que ele sabe denunciar quando são empregados por outros e que, conseqüentemente, vão de encontro a certas convicções que ele próprio transmitiu com toda a clareza:

“O que me parece mais digno de reflexão é que a Spielrein queira subordinar 0 material psicológico a pontos de vista biológicos; essa dependência deve ser rejeitada tanto como a dependência à filosofia, à fisiologia ou à anatomia do cérebro. A psicanálise farà da sè" (Correspondence, 1919-1914/ 1975, p. 230)

De tudo isso sobressai para nós que o conceito de pulsão de morte na obra de Freud foi gerado sobre fundamentos nos quais o próprio Freud se movimentava claramente de maneira contraditória, e não é de estranhar que, na hora de dar precisão a esse conceito dentro do pensamento psicanalítico pós-freudiano ele tenha dado ensejo a todo tipo de confusão, a um sem-fim de posições contrapostas.

Não obstante, é bem certo que a nova dicotomia proposta pela primeira vez em Além do princípio do prazer - como aponta J. Strachey em seu comentário de

\footnotetext{
${ }^{3} 0$ que aparece mais claramente na carta que Freud dirige a Jung poucos dias após a sessão mencionada, ao apresentar-Ihe a utilização que a srta. Spiel rein fizera durante sua conferência, como exemplo dessa maneira direta e imediata de servir-se da mitologia, enfatizando a esse propósito que
}

"eu defendo a proposta de que as formas manifestas dos motivos mitológicos não são diretamente utilizáveis para a comparação com nossos resultados psicanalíticos, mas que só o são suas formas latentes, originais, às quais é preciso remetê-los por meio de uma comparação histórica, com o fim de descartar as desfigurações que sofreram durante 0 desenvolvimento dos mitos". (Correspondence, 1975, p. 235) 
introdução a esta obra - teve "elaboração completa em 0 ego e o id (1923)" (FREUD, 1920, p. 6). Mas é preciso dizer também, a esse respeito, que a proposição desenvolvida por Freud nessa obra de 1923 favorece poderosamente 0 aspecto instintivista da pulsão de morte, à medida que a hipótese e a noção aí presentes de um id não recalcado e concebido como o primeiro ou como ponto de partida da tópica psíquica, não somente remete a uma tópica constituída de modo endogenista por delegação das funções vitais do organismo ou do somático no psíquico, mas também leva a determinados becos sem saída, como essa tentativa de reconstruir o mundo humano a partir de uma mônada de entrada fechada sobre si mesma, ou esse outro de fazer o ego derivar do id, o que torna inviável o estabelecimento de um ego como instância intrapsíquica e como limite ante 0 ataque pulsional.

Temos, então, que ressituar o conceito de pulsão de morte dentro de um enquadramento metapsicológico ordenador que ao menos reponha os termos "vida" e "morte" no plano do psíquico em contraposição ao biológico, já que só o psíquico é investigado pela "situação psicanalítica", por mais que a análise da dimensão psíquica depois tenha suas repercussões no funcionamento biológico singular.

U ma coisa é propor que a meta da pulsão de morte seja a descarga pulsional total sem nenhuma consideração para com o objeto e para com o próprio ego, em vista de seu movimento cego autodestrutivo; outra coisa muito diferente é essa assimilação, que se vê em Freud, da pulsão de morte a uma tendência de ordem natural à pura destruição, ou a um retorno de tipo cosmológico ao inorgânico, que surgiria com o aparecimento da vida e que definitivamente reduz o ser psíquico a um puro ser da natureza.

Nesse sentido, é fundamental enquadrar a pulsão de morte nos aspectos psicológicos da autodestruição e da des-ligação, em conexão com a descoberta freudiana inicial e transcendental de uma sexualidade anárquica ou fragmentada, auto-erótica, perversa, não genitalizada nem finalizada, em aberta ruptura ou descontinuidade com o natural instintivo ou adaptativo e que, certamente, remetia a um inconsciente recalcado no qual, e a partir do qual, configurava-se 0 pulsional.

Aspectos destrutivos e capazes de promover des-ligação, que não exigem ser percebidos sob a idéia da agressividade, compreendida esta como uma força psíquica independente da sexualidade 4 ou como uma força autônoma e origi-

\footnotetext{
${ }^{4} \mathrm{~N}$ a minha opinião, a agressi vidade no pensamento psicanalítico foi arrebatada do campo da sexual idade, à medida que não é concebida como ef ei to da intromissão da sexualidade inconsciente do outro adulto (que é real mente de onde emerge a sexualidade infantil) que se serve ou se apóia, para isso, precisamente nos cuidados que dedica ao bebê.
} 
nária, que remete a um dinamismo natural e inato, diferente do dinamismo sexual e oposto a ele.

Um entendimento que sem dúvida já aparece delineado dessa maneira na própria obra de Freud, quando em 0 mal- estar na civilização descreve o ser humano nos seguintes termos:

"O ser humano não é um ser manso, amável, no máximo capaz de defender-se se for atacado, mas é lícito atribuir à sua dotação pulsional uma boa dose de agressividade. Em conseqüência disso, o próximo não é apenas um possível auxiliar e objeto sexual, mas uma tentação para satisfazer nele a agressão, para usá-lo sexualmente sem seu consentimento, para despojá-lo de seu patrimônio, humilhá-lo, infligir-Ihe dores, martirizá-lo e assassiná-lo." (FREUD, 1930, p. 108)

e o qualifica pouco depois de "besta selvagem" ${ }^{5}$ colocando dessa maneira a agressão sádica do ser humano do lado da animalidade natural, quando é claro que no comportamento do animal em relação à sua presa não se deixa entrever sadismo algum nem prazer em causar sofrimento, de tal modo que na biologia animal, ou nessa animalidade biológica sobre a qual Freud pretende basear-se, nada há desse comportamento cruel, sádico e destrutivo, unicamente pelo pra zer de destruir que, no entanto, caracteriza o ser humano.

E nessas condições de conceituação a agressividade não vai ser pensada inscrevendo-se de forma fantasística nem como sexualizada, mas simplesmente como instintiva, ou como algo natural, já que em geral parte-se da idéia de um mundo definido por suas características hostis que ameaçam a segurança do organismo infantil, o qual vai ser protegido pela figura materna, que é considerada exclusivamente como agente capaz de proporcionar satisfação de necessidades - de modo algum como o agente que implanta a sexualidade por meio dos cuidados de autoconservação.

A este propósito parece-me fundamental ir ao encontro de uma das grandes confusões presentes ao longo da obra de Freud e, mais tarde, no pensamento pós-freudiano, que é a equivalência entre devir pulsional ou psicossexual (que tem uma genealogia ou uma seqüência específica, que a psicanálise descobre e conceitua por meio dos termos "auto-erotismo, narcisismo e escolha de objeto") e desenvolvimento do organismo psicobiológico ( que é de ordem não pulsional, não sexual ou de tipo de autoconservação e adaptativo).

Em vista dessa equivalência, ou dentro dessa hipótese profundamente infiltrada no pensamento freudiano, Freud propõe que desde o próprio início da vida, e

5 “Essa agressão cruel [...] desmascara os seres humanos como bestas selvagens que nem sequer respeitam os membros de sua própria espécie" (FREUD, 1930, p. 108, grifo nosso). 
em conseqüência da atividade muscular do organismo, está em ação uma agressividade por parte do sujeito infantil dirigida para o exterior, ou para o objeto externo que cuida dele, e também uma auto-agressão concebida como um processo real, até mesmo fisiológico, que consiste em dominar-se, em vencer a si mesmo: "não seria um total disparate construí-la [uma etapa anterior que desde o início se dirige a um objeto alheio] a partir dos esforços do bebê que quer assenhorear-se de seus próprios membros" (FREUD, 1915, p. 125).

Ademais, essa proposição levará Freud a apresentar a agressividade como uma força autônoma originária e independente da sexualidade: "a tendência agressiva é uma disposição pulsional autônoma, originária, do ser humano" (FREUD, 1930, p. 116).

Mas o problema está em que, proposta nesses termos, a agressividade remete a, ou impõe que se dê conta de uma força energética diferente da força energética sexual. Algo quanto a que Freud tinha-se acautelado perfeitamente e, por esse motivo, rejeitara na ocasião a idéia proposta por A. Adler com o nome de "pulsão de agressão", porém - como ele próprio será o primeiro a esquecer - logo se verá obrigado a recorrer a essa espécie de oposi ção metabiológica entre as pulsões de vida e as pulsões de morte, que em última análise contrapõe duas grandes forças instintivas enfrentadas de entrada no "organismo" humano. Forças que - partindo da idéia ${ }^{6}$ de que Freud descobriu primeiramente a ação da libido e mais tarde, impelido pela experiência clínica, a ação da agressão destrutiva - foram catalogadas colocando-se de um lado o libidinal e, do outro, 0 agressivo.

Ora, não apenas Freud sempre se opôs a postular uma energia específica para a agressividade ou para a pulsão destrutiva, mas também só se falarmos de uma mesma e única energia psíquica chamada sexual ou pulsional, poderemos dar conta das passagens e dos intercâmbios entre o sexual des-ligado e o sexual ligado, assim como só dessa maneira podemos levar a cabo o trabalho de transformação do des-ligado e atacante em ligado - que caracteriza por excelência a prática psicanalítica.

U ma vez que o funcionamento do pulsional no ser humano não se estabelece de maneira inata e mecânica, nem acontece por um princípio regulador básico que reparte a energia psíquica de modo mais ou menos homogêneo e contraposto, mas constitui-se em situação de sujeição às vicissitudes históricas da relação com o outro, na qual, e a partir da qual - ante o poder deste, por ser

\footnotetext{
${ }^{6}$ Idéia baseada na consideração de que o aparecimento da pulsão de morte no pensamento freudiano é todo uma nova descoberta, que se acrescenta de maneira cumulativa à descoberta inicial da sexualidade. Porém - como J. Laplanche aponta (LAPLANCHE, 1992, p. 279) - essa idéia não se sustenta quando se leva a cabo um minucioso estudo do movimento históricoconceitual que conduziu à segunda teoria pulsional.
} 
quem proporciona os cuidados de autoconservação e a sobrevivência - 0 pulsional não só se origina abrindo a possibilidade da construção do aparelho psíquico, arrancando o ser humano da natureza e da "estúpida existência", mas também como o verdadeiro motor do progresso psicológico: o pulsional também se estabelece como uma dinâmica que não se deixa evacuar e ligar, obstruindo e desestruturando o ego como instância intrapsíquica. Daí a cegueira que caracteriza o pulsional des-ligado e, de modo especial, o mais pulsional da pulsão, que é a pulsão de morte, que não tem outro fim senão a descarga imediata e a busca do idêntico sem reconhecimento de qualquer alteridade, e que termina sempre funcionando como modo de autodestruição ou de morte psíquica do eu.

Recebido em 13/ 4/ 2002. Aprovado em 9/ 5/ 2002.

\section{BIBLIOGRAFIA}

BLEICHMAR, S. ( 1993) La fundación del inconciente, BuenosAires, Amorrortu. FREUD, S. (1976) Obras completas, Buenos Aires, Amorrortu.

(1905) "Tres ensayos de teoría sexual", v. VII.

(1915) "Pulsiones y destinos de pulsión", v. XIV.

(1920) "Más allá del principio de placer", v. XVIII.

(1930) "El malestar en la cultura", v. XXI.

. \& JUNG, C. G. ( 1975) Correspondencel 910-1914, Paris, Gallimard.

LAPLANCHE, J. (1992) "La pulsion de mort dans la théorie sexuelle", in La révolution copernicienns inachevée, Paris, Aubier.

(1995/ 1997) La soi-disant pulsion de mort: une pulsion

sexuelle, Adolescence, v. 15, n. 2.

Les premiers psychanalystes. Minutes de la Société Psychanalytique deVienne, Paris, Gallimard, 1979.

REXAND, F. (1997) “L'évolution dela théorie freudienne du sexuel infantile entre 1905 et 1915 à partir des Minutes de la Société Psychanalytique de Vienne et desTrois essais sur la théorie sexuelle", tese de doutorado em Psicopatologia Fundamental e Psicanálise, Universidade de Paris VII.

JoséGutiérrez- Terrazas

Faculdade de Psicologia, UAM Campus de Cantoblanco

28049 Madri Espanha

Tel. + 34913975214

Fax + 34913975215

gutierrez.terrazas@uam.es 